Supporting Information for

\title{
A Chemically Coupled Antimony/Multi-Layer Graphene Hybrid as a High-Performance Anode for Sodium-Ion Batteries
}

Lingyun Hu, ${ }^{\dagger}$ Xiaoshu Zhu, ${ }^{,}$Yichen Du, ${ }^{\dagger}$ Yafei Li ${ }^{\dagger}$ Xiaosi Zhou, ${ }^{*}{ }^{\dagger}$ and Jianchun Bao ${ }^{*}$

${ }_{\dagger}^{\dagger}$ Jiangsu Key Laboratory of Biofunctional Materials, School of Chemistry and Materials

Science, Nanjing Normal University, Nanjing 210023, P. R. China

${ }^{\ddagger}$ Center for Analysis and Testing, Nanjing Normal University, Nanjing 210023, P. R. China

*(X.Z.) E-mail: zhouxiaosi@njnu.edu.cn. Tel./Fax: +86-25-85891027

*(J.B.) E-mail: baojianchun@njnu.edu.cn. Tel./Fax: +86-25-85891936 


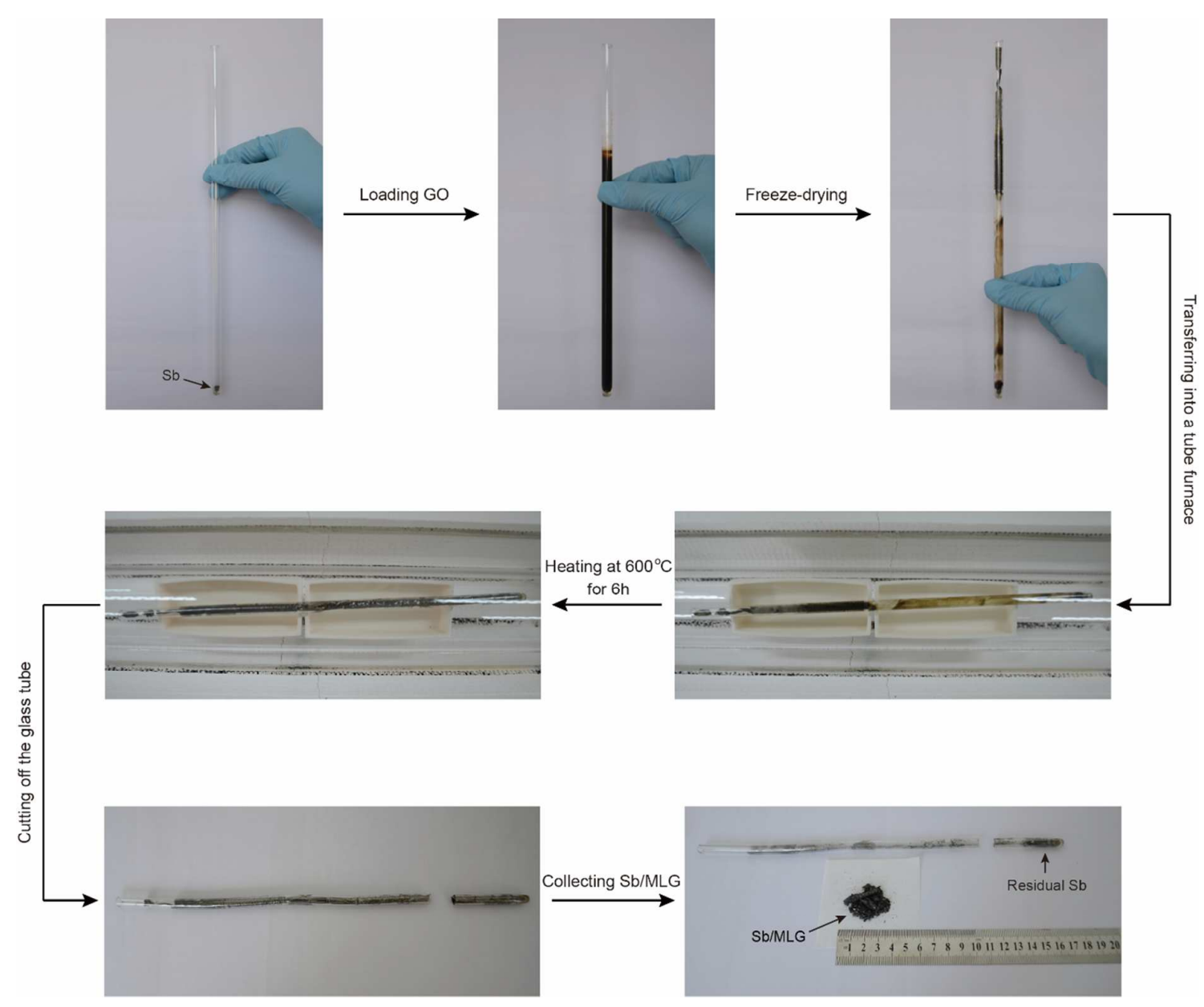

Figure S1. Photographs of the synthetic process and the as-formed Sb/MLG hybrid. 


\section{a)}

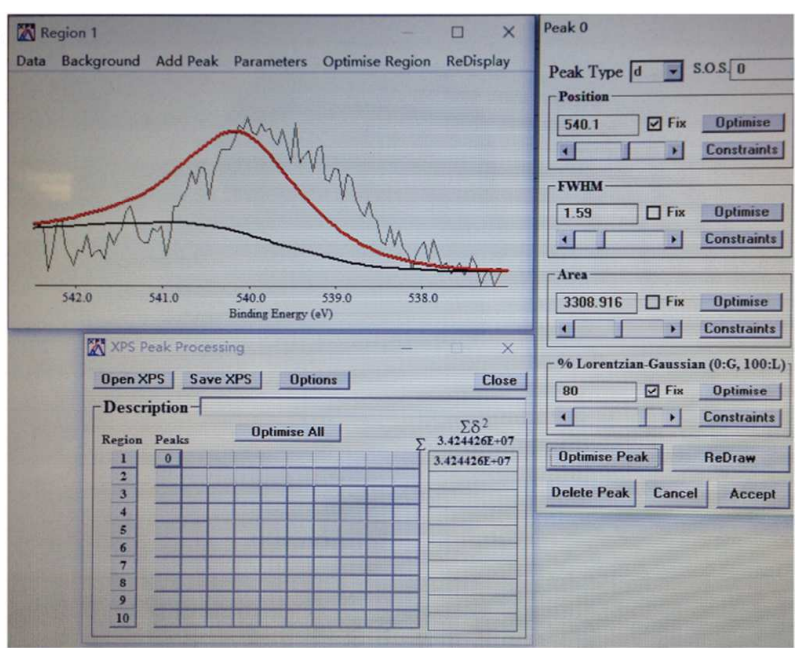

b)

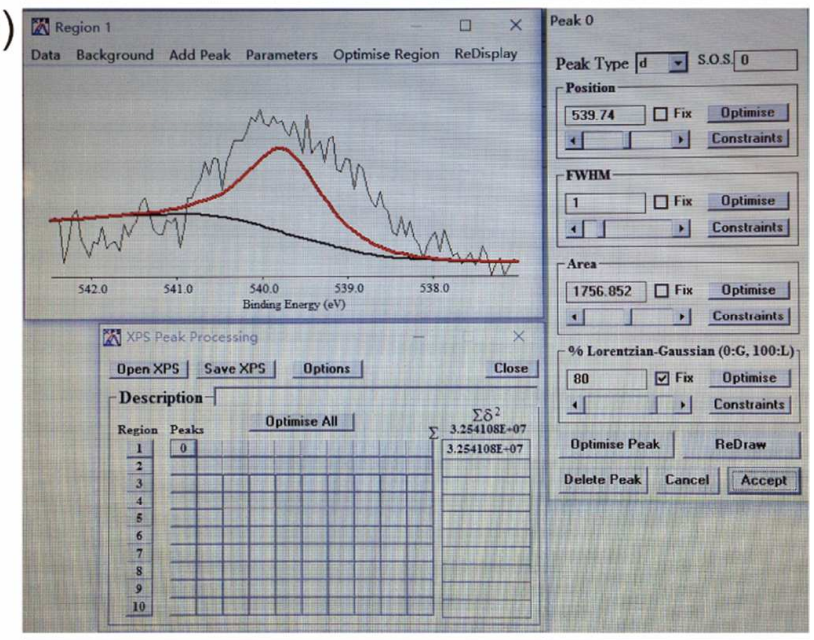

c)

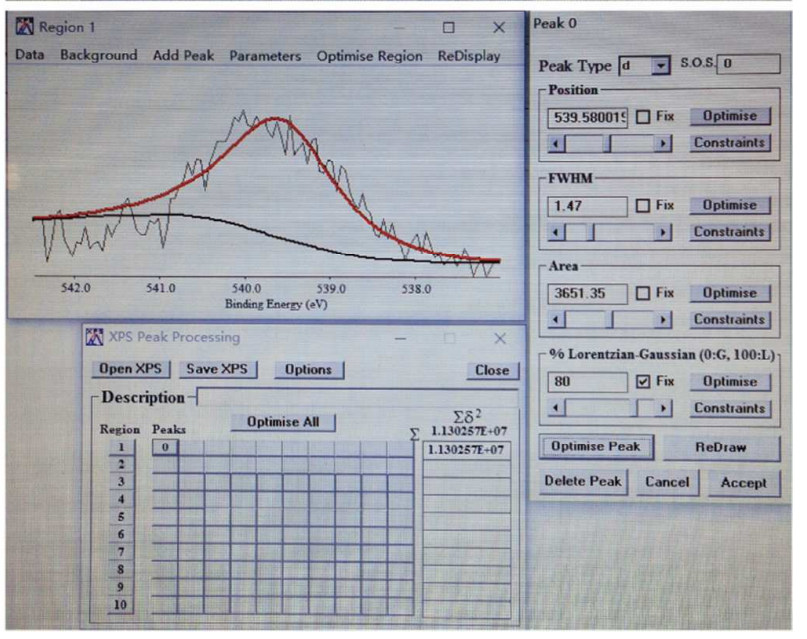

Figure S2. (a) The Sb 3d peak of the Sb/MLG hybrid is first artificially fixed at $540.1 \mathrm{eV}$ and then optimized by using the XPS fitting software (XPSPEAK.exe). Obviously, the fitting result is unsuitable. (b) The XPS fitting software is allowed to find the Sb 3d peak position of the $\mathrm{Sb} / \mathrm{MLG}$ hybrid by itself. The result shows the peak position is located at $539.7 \mathrm{eV}$. (c) 
The XPS fitting software performs optimization. The result shows the $\mathrm{Sb} 3 \mathrm{~d}$ peak position of the $\mathrm{Sb} / \mathrm{MLG}$ hybrid is finally centered at $539.6 \mathrm{eV}$.

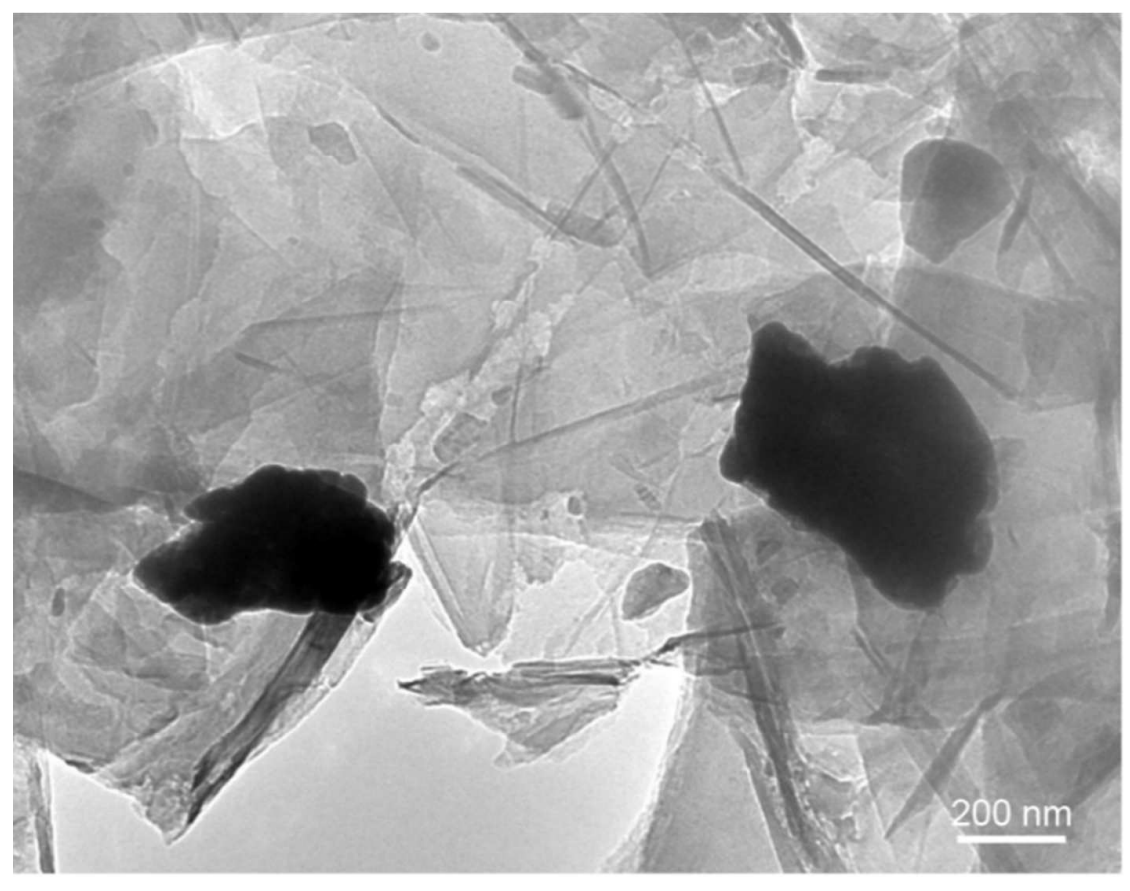

Figure S3. TEM image of the Sb-MLG mixture. 

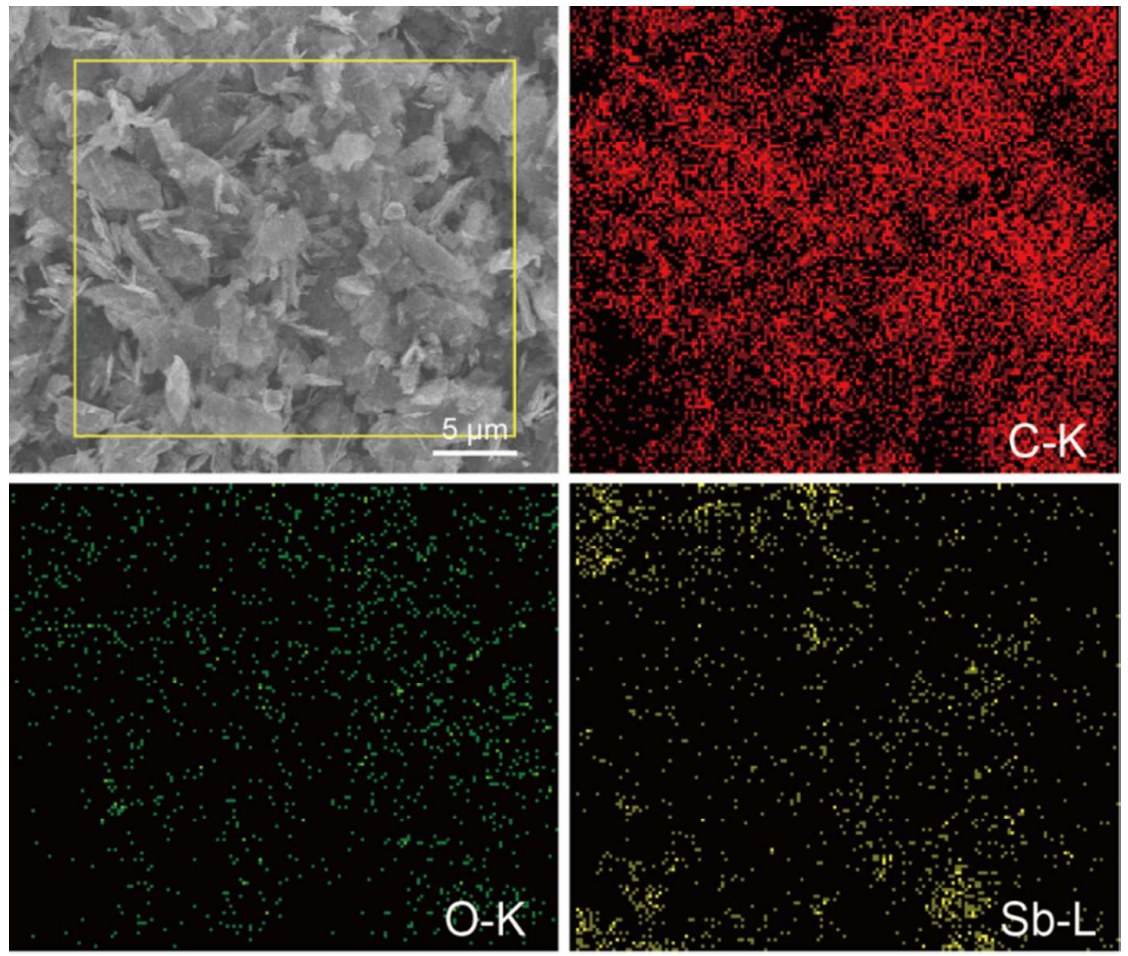

Figure S4. (a) SEM image and $(b-d)$ corresponding $\mathrm{C}, \mathrm{O}$, and $\mathrm{Sb}$ elemental mapping images of the Sb-MLG mixture. 

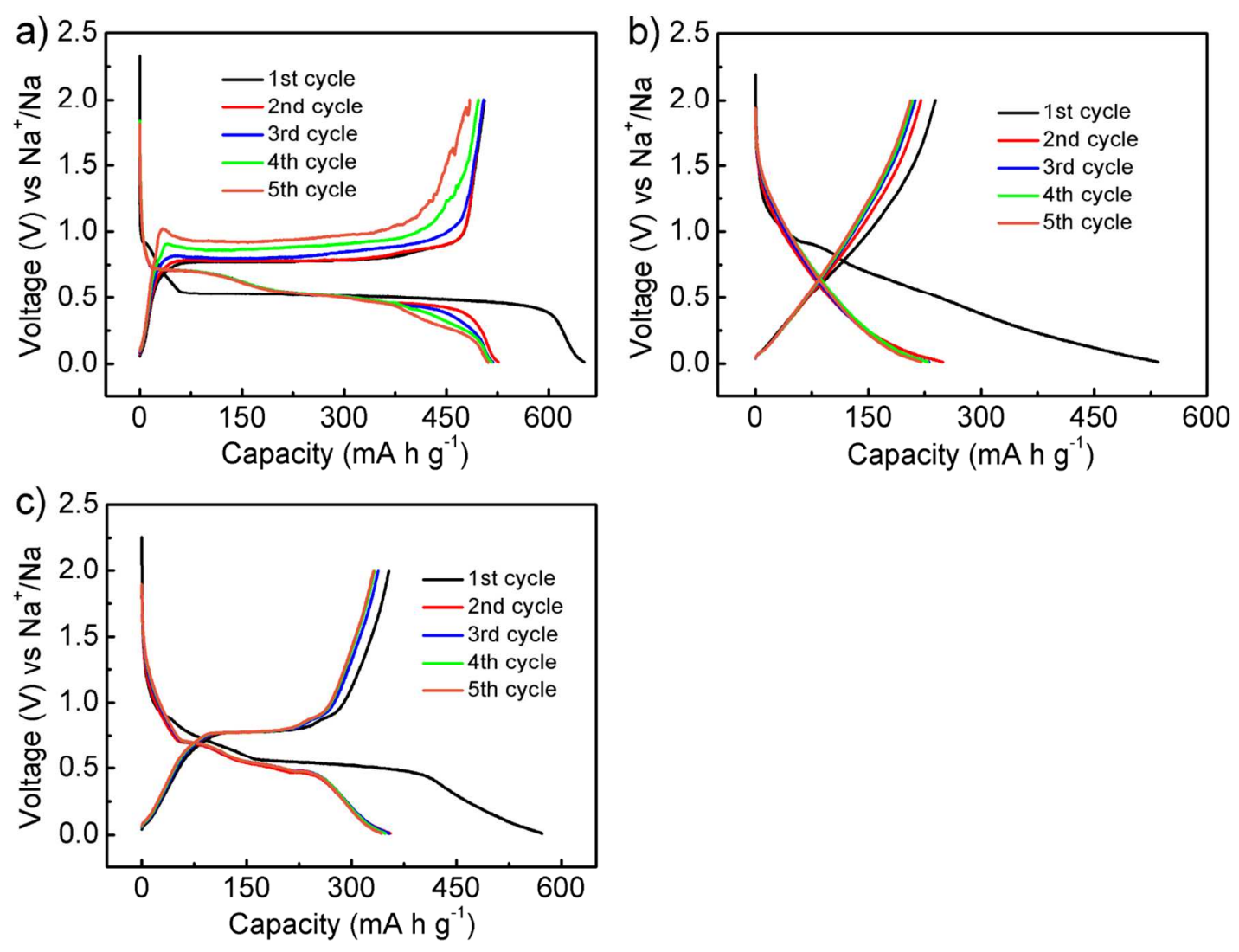

Figure S5. Galvanostatic charge-discharge profiles at a current density of $100 \mathrm{~mA} \mathrm{~g}^{-1}$ for (a) the $\mathrm{Sb}$ electrode, (b) the MLG electrode, and (c) the Sb-MLG mixture electrode. 


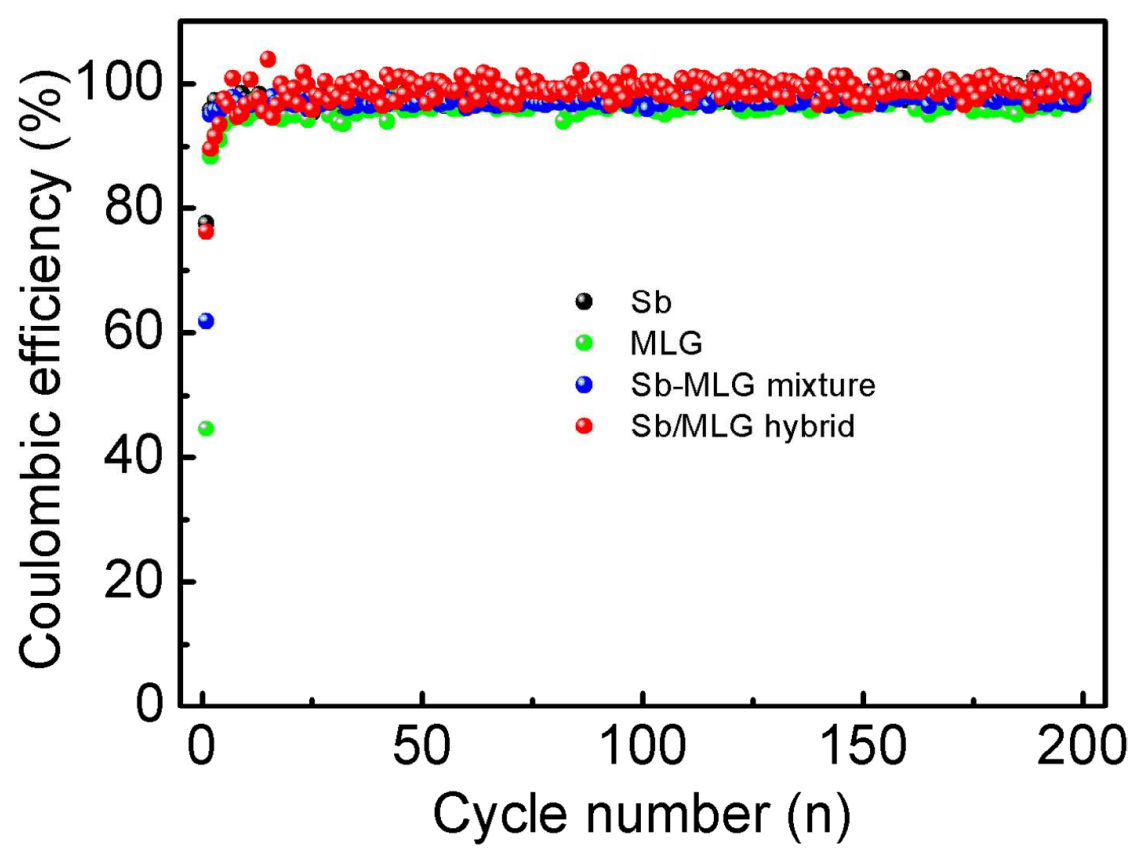

Figure S6. Coulombic efficiencies of the Sb, MLG, Sb-MLG mixture, and Sb/MLG hybrid electrodes at a current density of $100 \mathrm{~mA} \mathrm{~g}^{-1}$ for 200 cycles. 


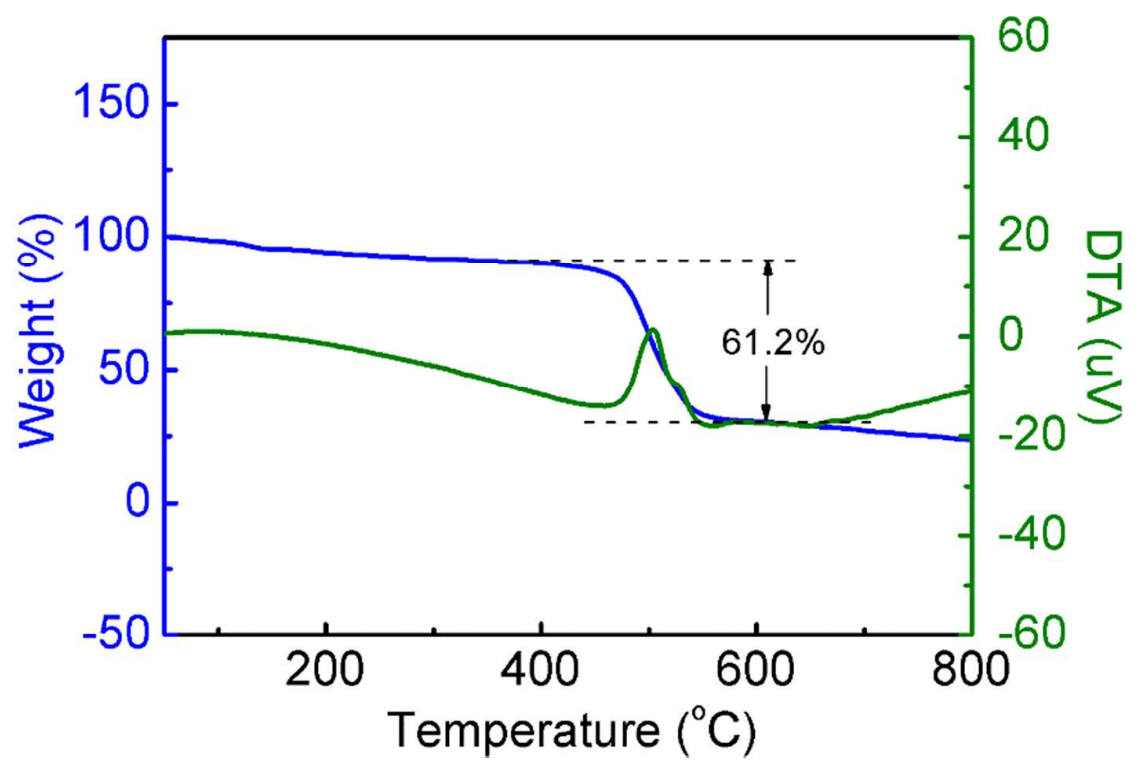

Figure S7. TGA and DTA curves of the Sb/MLG hybrid in air with a heating rate of $10^{\circ} \mathrm{C}$ $\min ^{-1}$ from room temperature to $800{ }^{\circ} \mathrm{C}$. The TGA and DTA profiles suggests that the MLG content in the $\mathrm{Sb} / \mathrm{MLG}$ hybrid is approximately $61.2 \mathrm{wt} \%$. Thus, the Sb content in the hybrid is around $38.8 \mathrm{wt} \%$. 

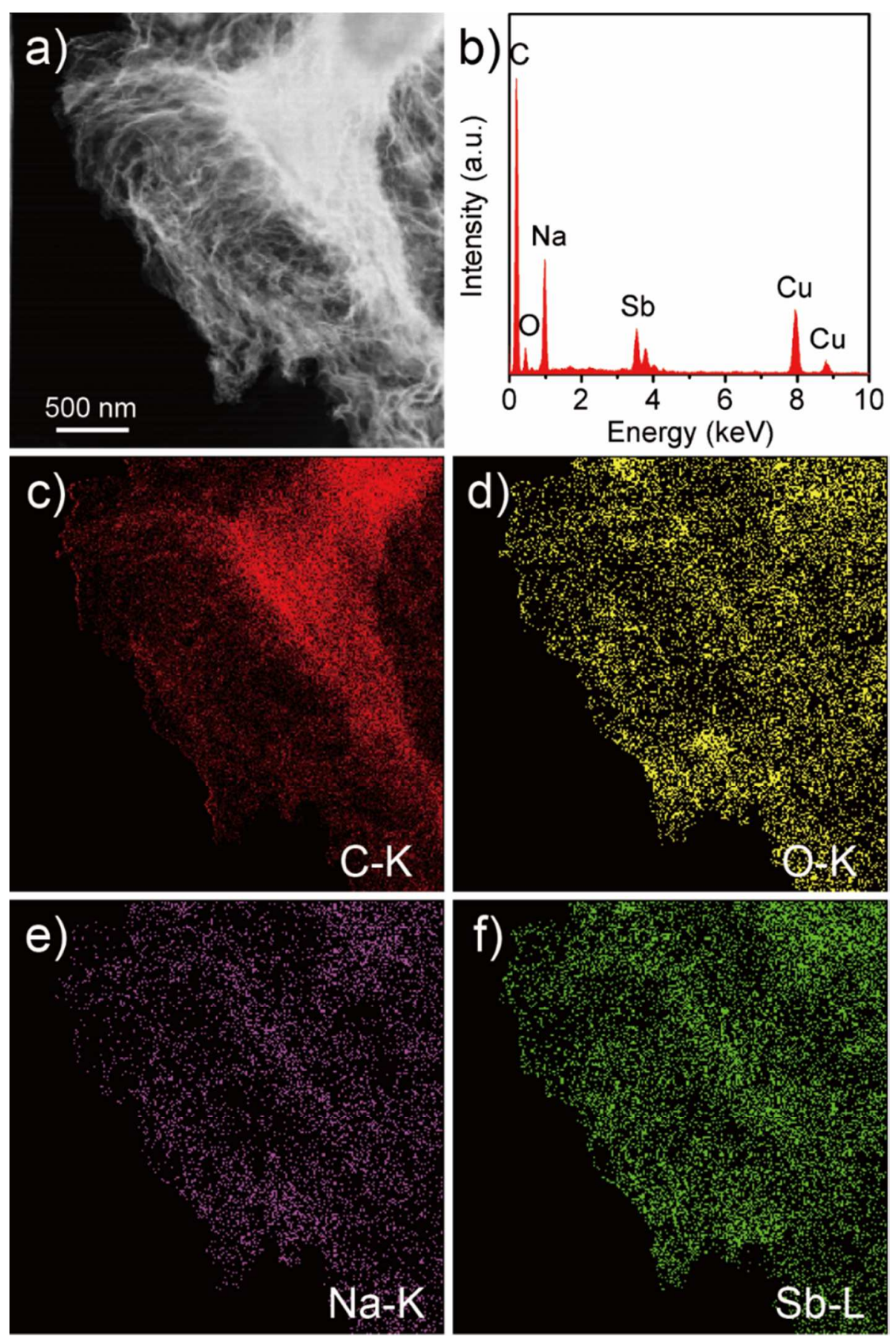

Figure S8. (a) STEM image, (b) EDX spectrum, and (c-f) EDX elemental mapping images of the cycled Sb/MLG hybrid electrode material. Both the remarkable Na signal in the EDX spectrum (Figure S7b) and the Na elemental mapping (Figure S7e) confirm the formation of the SEI film. 
Table S1. Electrochemical performances of different types of Sb-based anode materials for sodium-ion batteries.

\begin{tabular}{|c|c|c|c|c|c|c|c|}
\hline Materials & $\begin{array}{c}\text { Ratio of active } \\
\text { material } \\
(w t \%)\end{array}$ & $\begin{array}{c}\text { Voltage } \\
\text { range (V vs } \\
\left.\mathrm{Na}^{+} / \mathrm{Na}\right)\end{array}$ & $\begin{array}{c}\text { Mass } \\
\text { loading } \\
\left(\mathrm{mg} / \mathrm{cm}^{2}\right)\end{array}$ & $\begin{array}{l}\text { Current } \\
\text { density } \\
(\mathbf{m A} / \mathbf{g})\end{array}$ & $\begin{array}{c}\text { Initial } \\
\text { Coulombic } \\
\text { efficiency }\end{array}$ & $\begin{array}{l}\text { Charge } \\
\text { capacity } \\
(\mathrm{mA} / \mathbf{h} \text { g) }\end{array}$ & Reference \\
\hline SbNP@C & 100 & $0-2$ & $\sim 3 \mathrm{mg}$ & 100 & $55 \%$ & 440 & S1 \\
\hline $\begin{array}{c}\mathrm{Sb}-\mathrm{C} \\
\text { nanofibers }\end{array}$ & 70 & $0.01-2.5$ & $\sim 2.5$ & 200 & $56 \%$ & 495 & $\mathrm{~S} 2$ \\
\hline $\begin{array}{c}\mathrm{Sb} / \mathrm{MWCNT} \\
\text { nanocomposite }\end{array}$ & 80 & $0-2$ & $1.2-1.5$ & 100 & $69.7 \%$ & 502 & S3 \\
\hline $\mathrm{Sb}-\mathrm{N} / \mathrm{C}$ & 75 & $0.01-3.00$ & $1.0-2.0 \mathrm{mg}$ & 50 & $42.8 \%$ & 340.8 & S4 \\
\hline $\mathrm{Sb} / \mathrm{ICNNs}$ & 70 & $0.01-2$ & Not reported & 100 & $70.6 \%$ & 560.9 & S5 \\
\hline $\begin{array}{l}\mathrm{Sb} \text {-carbon } \\
\text { composite } \\
\text { microspheres }\end{array}$ & 70 & $0.001-2$ & Not reported & 300 & $64.3 \%$ & 402 & S6 \\
\hline $\begin{array}{c}\mathrm{Sb} / \mathrm{AB} \\
\text { composites }\end{array}$ & 70 & $0.01-2$ & $1.0-1.2 \mathrm{mg}$ & 100 & Not reported & 473 & S7 \\
\hline $\mathrm{Sb} / \mathrm{G}$ & 75 & $0.005-1.5$ & Not reported & 20 & $51.2 \%$ & 380 & S8 \\
\hline $\mathrm{rGO} / \mathrm{Sb}$ & 80 & $0.01-1.5$ & $1.02-1.05$ & 131 & $88 \%$ & 641 & S9 \\
\hline $\begin{array}{c}\mathrm{SiC}-\mathrm{Sb}-\mathrm{C} \\
\text { nanocomposites }\end{array}$ & 70 & $0.01-2.0$ & Not reported & 100 & $62.9 \%$ & 301 & S10 \\
\hline 10-Sb@C & 80 & $0.01-2.0$ & $\sim 0.8$ & 100 & $63.4 \%$ & 417 & S11 \\
\hline $\begin{array}{c}\mathrm{Sb} / \mathrm{C} \\
\text { nanocomposites }\end{array}$ & 80 & $0-2$ & 3 & 100 & $85 \%$ & 610 & S12 \\
\hline $\begin{array}{c}\text { Pure } \\
\text { micrometric } \\
\text { antimony }\end{array}$ & 70 & $0.01-1.5$ & 1.4 & $\mathrm{C} / 2$ & $\sim 65 \%$ & 537 & S13 \\
\hline $\mathrm{Sb} \mathrm{NCs}$ & 64 & $0-1.5$ & $0.5-1$ & 660 & $\sim 50 \%$ & $\sim 580$ & S14 \\
\hline $\mathrm{Sb} \mathrm{NCs}$ & 64 & $0.02-1.5$ & $\sim 0.5$ & 660 & $\sim 60 \%$ & $\sim 620$ & S15 \\
\hline Sb HNSs & 70 & $0.01-2$ & Not reported & 50 & $77 \%$ & 603 & S16 \\
\hline $\begin{array}{c}\mathrm{Sb} @ \mathrm{C} \\
\text { microspheres }\end{array}$ & 80 & $0-2.0$ & Not reported & 200 & $65 \%$ & 628 & S17 \\
\hline Sb PHMSs & 70 & $0.01-2$ & $1.0-1.2 \mathrm{mg}$ & 100 & $64.6 \%$ & 634.6 & S18 \\
\hline Sb films & 100 & $0-2$ & Not reported & $\mathrm{C} / 10$ & Not reported & 542 & S19 \\
\hline $\mathrm{Sb} / \mathrm{MLG}$ hybrid & 80 & $0.01-2$ & $1.0-1.5$ & 100 & $76.2 \%$ & 452 & This work \\
\hline
\end{tabular}

Note that the charge capacities are calculated based on the total mass of the composites except Ref. S12-19, in which the capacity values are normalized by the mass of Sb alone. 
Table S2. $R_{\mathrm{e}}, R_{\mathrm{f}}$, and $R_{\mathrm{ct}}$ obtained by fitting the experimental data in Figure $5 \mathrm{~b}$ using equivalent circuit (inset in Figure 5 b) for the Sb/MLG hybrid cell before cycling and after 30 and 100 cycles.

\begin{tabular}{cccc}
\hline & $R_{\mathrm{e}}(\Omega)$ & $R_{\mathrm{f}}(\Omega)$ & $R_{\mathrm{ct}}(\Omega)$ \\
Fresh cell & 8.8 & 104.7 & 11.1 \\
After 30 cycles & 9.5 & 54.5 & 8.0 \\
After 100 cycles & 13.9 & 53.8 & 7.6 \\
\hline
\end{tabular}

\section{References}

(S1) Zhu, Y.; Han, X.; Xu, Y.; Liu, Y.; Zheng, S.; Xu, K.; Hu, L.; Wang, C. Electrospun Sb/C Fibers for a Stable and Fast Sodium-Ion Battery Anode. ACS Nano 2013, 7, 6378-6386.

(S2) Wu, L.; Hu, X.; Qian, J.; Pei, F.; Wu, F.; Mao, R.; Ai, X.; Yang, H.; Cao, Y. Sb-C Nanofibers with Long Cycle Life as an Anode Material for High-Performance Sodium-Ion Batteries. Energy Environ. Sci. 2014, 7, 323-328.

(S3) Zhou, X.; Dai, Z.; Bao, J.; Guo, Y.-G. Wet Milled Synthesis of an Sb/MWCNT Nanocomposite for Improved Sodium Storage. J. Mater. Chem. A 2013, 1, 13727-13731.

(S4) Zhou, X.; Zhong, Y.; Yang, M.; Hu, M.; Wei, J.; Zhou, Z. Sb Nanoparticles Decorated N-Rich Carbon Nanosheets as Anode Materials for Sodium Ion Batteries with Superior Rate Capability and Long Cycling Stability. Chem. Commun. 2014, 50, 12888-12891.

(S5) Hou, H.; Jing, M.; Yang, Y.; Zhang, Y.; Song, W.; Yang, X.; Chen, J.; Ji. X. Antimony Nanoparticles Anchored on Interconnected Carbon Nanofibers Networks as Advanced Anode Material for Sodium-Ion Batteries. J. Power Sources 2015, 284, 227-235.

(S6) Ko, Y. N.; Kang, Y. C. Electrochemical Properties of Ultrafine Sb Nanocrystals 
Embedded in Carbon Microspheres for Use as Na-Ion Battery Anode Materials. Chem. Commun. 2014, 50, 12322-12324.

(S7) Hou, H.; Yang, Y.; Zhu, Y.; Jing, M.; Pan, C.; Fang, L.; Song, W.; Yang, X.; Ji, X. An Electrochemical Study of Sb/Acetylene Black Composite as Anode for Sodium-Ion Batteries. Electrochim. Acta 2014, 146, 328-334.

(S8) Zhang, Y.; Xie, J.; Zhu, T.; Cao, G.; Zhao, X.; Zhang, S. Activation of Electrochemical Lithium and Sodium Storage of Nanocrystalline Antimony by Anchoring on Graphene via a Facile In Situ Solvothermal Route. J. Power Sources 2014, 247, 204-212.

(S9) Nithya, C.; Gopukumar, S. rGO/Nano Sb Composite: A High Performance Anode Material for $\mathrm{Na}^{+}$Ion Batteries and Evidence for the Formation of Nanoribbons from the Nano rGO Sheet during Galvanostatic Cycling. J. Mater. Chem. A 2014, 2, 10516-10525.

(S10) Wu, L.; Pei, F.; Mao, R.; Wu, F.; Wu, Y.; Qian, J.; Cao, Y.; Ai, X.; Yang, H. SiC-Sb-C Nanocomposites as High-Capacity and Cycling-Stable Anode for Sodium-Ion Batteries. Electrochim. Acta 2013, 87, 41-45.

(S11) Zhang, N.; Liu, Y.; Lu, Y.; Han, X.; Cheng, F.; Chen, J. Spherical Nano-Sb@C Composite as a High-Rate and Ultra-Stable Anode Material for Sodium-Ion Batteries. Nano Res. 2015, 8, 3384-3393.

(S12) Qian, J.; Chen, Y.; Wu, L.; Cao, Y.; Ai, X.; Yang, H. High Capacity Na-Storage and Superior Cyclability of Nanocomposite Sb/C Anode for Na-Ion Batteries. Chem. Commun. 2012, 48, 7070-7072.

(S13) Darwiche, A.; Marino, C.; Sougrati, M. T.; Fraisse, B.; Stievano, L.; Monconduit, L. Better Cycling Performances of Bulk Sb in Na-Ion Batteries Compared to Li-Ion Systems: An Unexpected Electrochemical Mechanism. J. Am. Chem. Soc. 2012, 134, 20805-20811.

(S14) He, M.; Kraychyk, K.; Walter, M.; Kovalenko, M. V. Monodisperse Antimony Nanocrystals for High-Rate Li-ion and Na-ion Battery Anodes: Nano versus Bulk. Nano Lett. 2014, 14, 1255-1262.

(S15) Walter, M.; Erni, R.; Kovalenko, M. V. Inexpensive Antimony Nanocrystals and Their Composites with Red Phosphorus as High-Performance Anode Materials for Na-ion Batteries. Sci. Rep. 2015, 5, 8418 . 
(S16) Hou, H.; Jing, M.; Yang, Y.; Zhu, Y.; Fang, L.; Song, W.; Pan, X.; Ji, X. Sodium/Lithium Storage Behavior of Antimony Hollow Nanospheres for Rechargeable Batteries. ACS Appl. Mater. Interfaces 2014, 6, 16189-16196.

(S17) Wu, L.; Lu, H.; Xiao, L.; Ai, X.; Yang, H.; Cao, Y. Electrochemical Properties and Morphological Evolution of Pitaya-Like Sb@C Microspheres as High-Performance Anode for Sodium Ion Batteries. J. Mater. Chem. A 2015, 3, 5708-5713.

(S18) Hou, H.; Jing, M.; Yang, Y.; Zhang, Y.; Zhu, Y.; Song, W.; Yang, X.; Ji, X. Sb Porous Hollow Microspheres as Advanced Anode Materials for Sodium-Ion Batteries. J. Mater. Chem. A 2015, 3, 2971-2977.

(S19) Baggetto, L.; Ganesh, P.; Sun, C.-N.; Meisner, R. A.; Zawodzinski, T. A.; Veith, G. M. Intrinsic Thermodynamic and Kinetic Properties of Sb Electrodes for Li-Ion and Na-Ion Batteries: Experiment and Theory. J. Mater. Chem. A 2013, 1, 7985-7994. 